University of Konstanz

Department of Economics

\title{
Market Liberalization, Regulatory Uncertainty, and Firm I nvestment
}

Florian Baumann and Tim Friehe

Working Paper Series

2011-08 


\title{
Market Liberalization, Regulatory Uncertainty, and Firm Investment
}

\author{
Florian Baumann* Tim Friehe ${ }^{\dagger}$
}

May 5, 2011

\begin{abstract}
Motivated by the German postal market, this paper analyzes the effects of regulatory uncertainty about labor costs for investment into a liberalized market. We distinguish between the external investment margin (market entry) and the internal investment margin (technology) and establish that regulatory uncertainty affects these margins differently, encouraging market entry but discouraging investment at the internal margin. As a consequence, the impact of regulatory uncertainty on competition in liberalized markets is the result of these two countervailing forces.
\end{abstract}

Keywords: regulatory uncertainty, investment, market entry, minimum wage

JEL-Classification: D43, J38, L13

*Corresponding author: Eberhard Karls University Tübingen, Department of Economics, Melanchthonstr. 30, 72074 Tübingen, Germany. E-mail: florian.baumann@uni-tuebingen.de

${ }^{\dagger}$ University of Konstanz, Department of Economics, Box 136, 78457 Konstanz, Germany. E-mail: tim.friehe@uni-konstanz.de. We would like to thank Laszlo Goerke for fruitful discussions. 


\section{Introduction}

In recent years, various formerly state-controlled markets have been liberalized in many countries. Examples include markets for electricity, gas, transportation, water, and communication. At the outset, these markets were controlled by state-owned monopolies and one of the objectives of liberalization was to induce market entry by competitive firms. Competitiveness of new firms usually requires investment into technology used. This study focusses on market entry and investment into competitiveness in the presence of uncertainty about regulatory intervention in the market and assesses the impact of such uncertainty on the aim of introducing competition.

Given the strong and often undisputed market position of formerly state-controlled firms before liberalization of markets, these firms often granted their employees very favorable working conditions in terms of wages and other benefits. Following liberalization, these conditions often could not be removed for legal reasons. One pertinent question is to what extent regulatory intervention will confer these benefits to employees of new competitors, seeking a level playing field with the incumbent firm. Given that there often is a prolonged political debate as parties often disagree in their views, cost uncertainty for new and potential entrants arises. A case at hand is the German postal market dominated by the former monopolist Deutsche Post. ${ }^{1}$ The postal market was greatly liberalized in the beginning of 2008, allowing for market entry of private companies into the market for letters. However, parallel to these changes, there emerged a discussion about the introduction of a minimum wage by making use of a law labeled Entsendegesetz (Posted Worker Act), which is a construct allowing the conferral of union-bargained wages to the whole sector. In 2008, this minimum wage came into effect. The corresponding wages considerably increased labor costs of new entrants. In contrast, labor costs of the Deutsche Post remained more or less unaffected since wages at Deutsche Post were high to start with. Subsequently, the introduction of the minimum wage was challenged in court by the newly entered postal firms and finally ruled void in January 2009, the court's arguments relying on the missing consultation of new firms. Whether a renewed attempt for the introduction of the minimum wage will be undertaken remains uncertain. All in all, the situation is one of uncertainty about labor costs for new competitors

\footnotetext{
${ }^{1}$ For a more extensive discussion of the legal background, see, e.g., Heitzler and Wey (2010).
} 
of the Deutsche Post. It has been argued that these circumstances seriously lower investment incentives of potential entrants (e.g., 'Bitte kippen!', Die Zeit January 21, 2010). We seek to establish the repercussions of this kind of regulatory uncertainty for market entry and technology investment decisions in a simple theoretical framework.

The effect of uncertainty on investment decisions has been extensively discussed within the real-option approach, where the focus is on the timing of investment (see, e.g., Dixit and Pindyck 1994). In contrast, we focus on the distinction between the internal and external investment margin and analyze a static framework, thereby excluding deferral of investment. In a related study, Tyagi (2006) provides an analysis regarding uncertainty in the context of the introduction of a new product. In addition, uncertainty in oligopoly settings has been discussed widely for the case in which uncertainty is resolved only after quantity/price decisions have been taken and firms may decide on costly information acquisition (see, e.g., Vives 1999, Christen 2005). In our setup, quantity/price decisions are taken after uncertainty has been resolved.

The structure of the paper is as follows. In Section 2, we present the model applied. The analysis of this model is laid out in Section 3. Section 4 offers concluding remarks.

\section{The model}

Our model takes up characteristics of the German postal market in a stylized way. We consider a market for a homogeneous product with an indirect demand function $p=\alpha-\beta Q$, where $Q$ is the amount of the good traded and $\alpha, \beta>0$. There is an incumbent firm, $M$, endowed with production technology $q_{M}=a_{M} l_{M}$, where $q_{M}, a_{M}, l_{M}$ denote output, labor productivity, and labor input. The incumbent might be challenged by a new entrant, $E$. Upon entry, $E$ decides on technology investment $T$ which determines labor productivity according to $a_{E}(T)$, where $a_{E}^{\prime}(T)>0, a_{E}^{\prime \prime}(T) \leq 0$. This represents the internal investment margin. The output of the entrant then follows from $q_{E}=a_{E}(T) l_{E}$. Market entry, the external investment margin, is associated with fixed costs $K$, drawn from an interval $[\underline{K}, \bar{K}]$ according to the cumulative distribution function $G(K)$. We assume that, for instance due to long-standing contracts, the incumbent is legally required to pay a wage equal to $w_{M}$. 
For the potential entrant $E$, there is regulatory uncertainty about the wages it has to pay. A priori, before the decisions on market entry and technology investment are taken, only the distribution for the corresponding wage $w_{E}$ is known. For parsimony, $w_{E}$ is assumed to be uniformly distributed in the interval $[m-\sigma / 2, m+\sigma / 2]$, implying a density of $1 / \sigma$. These assumptions allow for an easy distinction between changes in the level of the expected wage and changes in the spread of the expected wage. In the following, we interpret $\sigma$ as the measure for uncertainty and focus our analysis on it. Relating this to our example of the German postal market, we argue that there may be a regulatory intervention when it comes to the level of entrant wages in order to limit the potential discrepancy to the incumbent's wage. However, the actual wages prescribed by the regulator as well as legality of the intervention are subject to uncertainty. The analysis in the next section will focus on the repercussions of an increase in precisely this regulatory uncertainty, i.e., $\sigma$.

The time structure of the game played can be summarized as follows. At Stage 0 of the game, competitor $E$ decides on market entry after observing the realization of entry costs $K$. At Stage 1, and given market entry, firm $E$ determines technology investment $T$ before, at Stage 2, the wage $w_{E}$ is realized and production takes place. Competition at Stage 2 is assumed to be in labor inputs which are chosen simultaneously with $l_{E}$ denoting firm $E$ 's labor input. ${ }^{2}$ We solve the model by backward induction.

\section{The analysis}

The model detailed in the previous section is kept simple in many ways. However, this eases to bring the central aspect of this study to the fore, which is identifying the repercussions of regulatory uncertainty on potential entrants' investment at the external and the internal investment margin. The analysis starts at the last stage, where firms determine profitmaximizing levels of labor input for given investment decisions made at the earlier stages.

\footnotetext{
${ }^{2}$ Neither the consideration of price competition with heterogeneous goods nor the possibility of the incumbent acting as Stackelberg leader would impact our qualitative findings.
} 
Stage 2: Firm $j$ 's profits, $j=E, M$, are given by

$$
\pi_{j}=\left(\alpha-\beta\left(a_{j} l_{j}+a_{i} l_{i}\right)\right) a_{j} l_{j}-w_{j} l_{j}
$$

with $i=E, M$ and $i \neq j$. Objective function (1) gives rise to the first-order condition for an interior solution ${ }^{3}$

$$
\frac{\partial \pi_{j}}{\partial l_{j}}=a_{j}\left(\alpha-\beta a_{i} l_{i}-2 \beta a_{j} l_{j}\right)-w_{j}=0 \quad i, j=E, M ; j \neq i
$$

Solving for equilibrium labor inputs, we arrive at

$$
l_{j}=\frac{\alpha-2 \frac{w_{j}}{a_{j}}+\frac{w_{i}}{a_{i}}}{3 \beta a_{j}}
$$

which corresponds with standard results in industrial organization (see, e.g., Tirole 1988). From (3), it is clear that a comparatively low wage implies a comparatively large market share, all else equal. It is precisely this comparative advantage new entrants might enjoy that motivates formerly state-owned incumbents to lobby for a transferral of employees' rights to new competitors.

For the analysis of investment decisions, an entrant's profits are decisive. For a given wage $w_{E}$ and investment $T$, these profits are given by

$$
\pi_{E}^{*}=\frac{\left(\alpha+\frac{w_{M}}{a_{M}}-2 \frac{w_{E}}{a_{E}(T)}\right)^{2}}{9 \beta}
$$

Regarding notation, we asterisk the objective function which uses the privately optimal levels of decision variables. For later use, we report comparative statics results with respect to wages and technology investment. In line with intuition, an entrant's profits decrease in wages $w_{E}$ and increase in the investment level $T$,

$$
\begin{gathered}
\frac{\partial \pi_{E}^{*}}{\partial w_{E}}=-\frac{4\left(\alpha+\frac{w_{M}}{a_{M}}-2 \frac{w_{E}}{a_{E}(T)}\right)}{9 \beta a_{E}(T)}=-\frac{2}{3} l_{E}<0 \\
\frac{\partial \pi_{E}^{*}}{\partial T}=\frac{4\left(\alpha+\frac{w_{M}}{a_{M}}-2 \frac{w_{E}}{a_{E}(T)}\right) w_{E}}{9 \beta a_{E}(T)^{2}} a_{E}^{\prime}(T)=\frac{2}{3} w_{E} l_{E} \frac{a_{E}^{\prime}(T)}{a_{E}(T)}>0
\end{gathered}
$$

With $\frac{w_{E}}{a_{E}(T)}$ as the unit costs of firm $E$, a higher level of $w_{E}$ makes firm $E$ relatively less competitive, whereas a higher level of $T$ makes firm $E$ relatively more competitive. This completes the description of Stage 2 of the game.

\footnotetext{
${ }^{3}$ Corner solutions could be allowed for without affecting our main results.
} 
Stage 1: Firm $E$ determines investment $T$ to maximize expected profits net investment cost, $\Pi_{E}$, i.e.

$$
\max _{T} \Pi_{E}=\int_{m-\sigma / 2}^{m+\sigma / 2} \frac{\pi_{E}^{*}\left(w_{E}\right)}{\sigma} d w_{E}-T
$$

The first-order condition corresponding to (7) results as

$$
\frac{\partial \Pi_{E}}{\partial T}=\int_{m-\sigma / 2}^{m+\sigma / 2} \frac{\partial \pi_{E}^{*}\left(w_{E}\right) / \partial T}{\sigma} d w_{E}-1=0
$$

where we assume that the second-order condition is fulfilled. ${ }^{4}$ Condition (8) demonstrates that the marginal benefit of more investment at the internal investment margin is the expected increase in profits at Stage 2, as laid out in (6). The expectation operator is due to regulatory uncertainty.

Given an interior solution for the optimal level of $T$, we determine how optimal investment is affected by the measure for regulatory uncertainty $\sigma$. Starting from $\frac{\partial T}{\partial \sigma}=-\frac{\partial^{2} \Pi_{E}}{\partial T \partial \sigma} / \frac{\partial^{2} \Pi_{E}}{\partial T^{2}}$, the cross-derivative of interest is given by

$$
\frac{\partial^{2} \Pi_{E}}{\partial T \partial \sigma}=\frac{1}{\sigma}\left(\frac{1}{2} \frac{\partial \pi_{E}^{*}(m+\sigma / 2)}{\partial T}+\frac{1}{2} \frac{\partial \pi_{E}^{*}(m-\sigma / 2)}{\partial T}-\int_{m-\sigma / 2}^{m+\sigma / 2} \frac{\partial \pi_{E}^{*}\left(w_{E}\right) / \partial T}{\sigma} d w_{E}\right)
$$

The statement (9) shows that the influence of an increase in $\sigma$ on optimal investment depends on the curvature of $\partial \pi_{E}^{*}\left(w_{E}\right) / \partial T$ with respect to the wage $w_{E}$. The first two terms in the parentheses represent a convex combination of the derivative evaluated at the upper and lower bound of integration, whereas the third term takes account of the actual values of the derivative for all levels of $w_{E}$ in $[m-\sigma / 2, m+\sigma / 2]$. Since

$$
\frac{\partial}{\partial w_{E}} \frac{\partial \pi_{E}^{*}\left(w_{E}\right)}{\partial T}=\frac{4\left(\alpha+\frac{w_{M}}{a_{M}}-4 \frac{w_{E}}{a_{E}(T)}\right)}{9 \beta a_{E}(T)^{2}} a_{E}^{\prime}(T)
$$

we establish that

$$
\frac{\partial^{2}}{\partial w_{E}^{2}} \frac{\partial \pi_{E}^{*}\left(w_{E}\right)}{\partial T}=-\frac{16 a_{E}^{\prime}(T)}{9 \beta a_{E}(T)^{3}}<0
$$

As a consequence, we assert that the derivative of profits with respect to technology investment is a strictly concave function of the wage $w_{E}$, i.e., the impact of a higher level of $w_{E}$ on the desirability of technology investment is diminishing in the wage. Accordingly, optimal investment depends negatively on uncertainty measured by $\sigma$,

$$
\frac{\partial T}{\partial \sigma}<0
$$

The above arguments are summarized in the following result:

\footnotetext{
${ }^{4}$ Corner solutions could result as expected profits are not necessarily concave in investment $T$.
} 
Proposition 1 The profit-maximizing investment at the internal margin is decreasing in the uncertainty measure.

This finding can be explained as follows. An increase in the wage reduces labor input which makes investment less profitable because the cost saving effect applies to fewer output units. With labor input decreasing linearly in the wage, see (3), this effect is more pronounced for higher wages. This explains the concavity of the partial derivative and translates into diminished incentives for technology investments when uncertainty is higher.

As a next step in our analysis of the investment repercussions of regulatory uncertainty, we turn to Stage 1 at which the entrant takes the entry decision.

Stage 0: The entry decision can be described by a comparison of fixed entry costs $K$ and expected profits net investment costs $\Pi_{E}^{*}$. Note that $\Pi_{E}^{*}$ incorporates the privately optimal decisions on technology and labor input. With $K$ being drawn from the cumulative distribution function $G(K)$ and market entry occurring for $\Pi_{E}^{*} \geq K$, the probability for market entry is given by $G\left(\Pi_{E}^{*}\right)$ and is increasing in $\Pi_{E}^{*}$. We show that the likelihood of market entry increases in the uncertainty parameter $\sigma$. The derivative of expected profits with respect to $\sigma$ is given by

$$
\frac{\partial \Pi_{E}^{*}}{\partial \sigma}=\frac{1}{\sigma}\left(\frac{1}{2} \pi_{E}^{*}(m+\sigma / 2)+\frac{1}{2} \pi_{E}^{*}(m-\sigma / 2)-\int_{m-\sigma / 2}^{m+\sigma / 2} \frac{\pi_{E}^{*}\left(w_{E}\right)}{\sigma} d w_{E}\right)
$$

and its sign therefore depends on the sign of the second derivative of profits $\pi_{E}^{*}\left(w_{E}\right)$ with respect to the wage $w_{E}$. From equation (5) we find

$$
\frac{\partial^{2} \pi_{E}^{*}\left(w_{E}\right)}{\partial w_{E}^{2}}=\frac{8}{9 \beta a_{E}(T)^{2}}>0
$$

which establishes a strictly convex relationship. In consequence, the derivative of expected profits with respect to the uncertainty measure $\sigma$ is positive, implying an increase in the probability of market entry for higher values of $\sigma$. This finding can be summarized as follows:

Proposition 2 An increase in the uncertainty measure is (weakly) favorable for profitmaximizing investment at the external margin, i.e., market entry becomes more likely. 
The argument for this finding goes as follows. The convex relationship between profits and the wage stems from the fact that the firm adjusts labor input according to wages. Higher wages reduce optimal labor input according to higher labor costs. As the firm is able to adjust labor input, profits are a strictly convex function of labor costs, i.e., the second derivative is positively signed. This translates into higher expected profits net investment costs when uncertainty about wages rises.

This study addresses the impact of regulatory uncertainty on investment. It is established in Proposition 1 that the popular claim of uncertainty decreasing investment holds at the internal investment margin. In contrast, as detailed in Proposition 2, market entry is actually more likely in a setting characterized by regulatory uncertainty. As a result, it is not clear that the presence of regulatory uncertainty hinders the often formulated policy objective of turning formerly state-controlled industries into competitive markets.

\section{Conclusion}

This paper focuses on industries in which there is a strong, previously state-owned incumbent as is the case in the German postal market. Firms such as Deutsche Post are in some ways disadvantaged due to institutional arrangements inherited from former times. Given this setting, one policy question is to what extent regulatory intervention will impose similar arrangements on new competitors in the pursuit of creating a level playing field with incumbent firms. This creates regulatory uncertainty. In our study, we have explored the popular claim that such regulatory circumstances seriously lower investment incentives of potential entrants.

In summary, our analysis indicates that while regulatory uncertainty about the level of labor costs decreases incentives for technology investments, it increases the probability of market entry. In consequence, regulatory uncertainty does not necessarily worsen the prospect of inducing competition in formerly state-run industries. All in all, the results contribute to the insight that the evaluation of investment incentives in the presence of regulatory uncertainty demands a detailed analysis instead of quickly jumping to conclusions based on gut feelings. 


\section{References}

Christen, M., 2005. Cost Uncertainty is Bliss: The Effect of Competition on the Acquisition of Cost Information for Pricing new Products, Management Science 51, 668-676.

Dixit, A., Pindyck, R. 1994. Investment under Uncertainty, Princeton University Press, Princeton.

Heitzler, S., Wey, C. 2010. Raising Rivals' Fixed (Labor) Costs: The Deutsche Post Case, DIW Berlin Discussion Paper No. 1008.

Tirole, J., 1988. The Theory of Industrial Organization, MIT Press, Cambridge, Mass.

Tyagi, R. 2006. New Product Introductions and Failures Under Uncertainty, International Journal of Research in Marketing 23, 199-213.

Vives, X., 1999. Oligopoly Pricing: Old Ideas and new Tools, MIT Press, Cambridge, Mass. 